\title{
Inventory Management: An Impetus for Increased Profitability in Manufacturing Firms
}

\author{
Adebola Daniel Kolawole ${ }^{1, *}$, Adesola Busola Akomolafe ${ }^{1}$, Babatunde Johnson Olusipe ${ }^{2}$ \\ ${ }^{1}$ Department of Accounting, Afe Babalola University, Ado-Ekiti, Nigeria \\ ${ }^{2}$ Department of Agriculture Economics, Afe Babalola University, Ado-Ekiti, Nigeria
}

Email address:

adebola.kolawole@abuad.edu.ng (A. D. Kolawole)

${ }^{*}$ Corresponding author

\section{To cite this article:}

Adebola Daniel Kolawole, Adesola Busola Akomolafe, Babatunde Johnson Olusipe. Inventory Management: An Impetus for Increased Profitability in Manufacturing Firms. International Journal of Accounting, Finance and Risk Management. Vol. 4, No. 4, 2019 , pp. 110-115. doi: $10.11648 /$ j.ijafrm.20190404.12

Received: August 27, 2019; Accepted: September 29, 2019; Published: November 25, 2019

\begin{abstract}
This study evaluated the degree of relationship between inventory management and profitability of manufacturing firmsin Nigeria. International Breweries Plc was adopted as case study. Secondary data were sourced from the company's annual reports for the period of 10 years. A simple linear regression model was specified to test the correlation between variables used. Stock turnover ratio was used to capture the relationship between costs of sales incurred in generating total revenue and the inventory utilized in for production and distribution. The result generated from the study showed that the company operates an efficient Inventory Management System which has strong influence on its profitability. The correlation coefficient (r) was $85.3 \%$ while $\mathrm{r}^{2}$ was $72.7 \%$. The study concluded that the efficient inventory management contributed significantly to profitability of manufacturing companies. The study recommended that manufacturing firms should focus on improving on their inventory management system by adopting a more efficient approach in utilizing inventory items.
\end{abstract}

Keywords: Inventory Management, Profitability, Gross Profit, Stock Turnover Ratio

\section{Introduction}

Inventory is one of the biggest corporate assets in the manufacturing industry. It comprises raw materials, component parts, work-in-process, and/or finished products held at a location in the supply chain. Inventory constitutes a significant part of current assets of manufacturing companies in Nigeria. Such large size of inventory maintained by organizations is backed by considerable amount of funds committed to them. It is therefore, imperative to manage inventories efficiently and effectively in order to avoid and prevent wastage of investment. A firm neglecting the management of inventories will be jeopardizing its long-run profitability and may fail ultimately. Inventory management is vital in the control of materials and goods that have to be held for later use in the case of production. Profit maximization is a key objective of most businesses [1]. This expected level of profit enables companies to have advantage of business opportunities, undertake research and innovation which make for growth and survival. Investment in inventories is one major component of cost in many manufacturing organizations which should be managed efficiently to ensure profitability. The profitability of any business organization depends largely on the ability of management to exercise effective purchasing and efficient materials control [4]. Inventory management is a critical success factor for manufacturing companies as it involves the use and control of inventory. This is influenced by the ability of management to carefully and efficiently decide on when to increase or maintain stock level based on stock usage in order to achieve the targeted output. Decision in relation to management of inventory could be seen as one of the strategic decisions of a company because it affects its operational efficiency and to a large extent determine the future prospects of the company. The effective inventory management can make a significant contribution to a company's profit as well as increase its return on total assets [1]. They emphasized that long run profitability as well as continuity of business concern when its inventories are left 
unmanaged will be exposed to danger. This study considers how inventory in manufacturing companies are being managed since the basic goal of a manufacturing concern is to maintain a level of inventory that will provide optimum stock at lowest cost. The study thus seeks to increase knowledge on the inventory management system and techniques employed by manufacturing concern as it affects productivity and profitability given that few studies have been conducted in this area $[1,4,6]$.

\section{Conceptual Clarifications}

\section{Inventory Management}

Inventory management is a critical component of profitability. It can be deemed to be effective when it is premised upon a system to keep track of inventory, a reliable forecast of demand, adequate knowledge of lead times, reasonable estimates of holding costs, ordering costs and shortage costs. A good classification system should be in place as any lapses observed in inventory management could cause losses due to shrinkage or pilferage. A company's management has the responsibility to ensure control of its inventory through application of techniques such as: good personnel selection, training, and discipline, tight control on incoming shipments and effective control on all goods leaving facility. Inventory Management is considered imperative as it provides acceptable level of customer service (i.e. on-time delivery), allow cost-efficient operations and minimize inventory investment. Inventory management refers to all the activities involved in developing and managing the inventory levels of raw materials, semifinished materials (work-in-progress) and finished good [8]. Inventory management in its broadest perspective is to keep the most economical amount of one kind of asset in order to facilitate an increase in the total value of all assets of the organization - human and material resources [12]. Company's management are constantly faced with typical question such as; what should be the order quantity (Q), when should an order be placed, i.e. reorder point (ROP), and how much safety stock (SS) should be maintained? A convenient classification of the types of inventory is as follows: Raw materials - the materials, components used in manufacture of products which are purchased but not yet processed; Work-in-progress - partly finished goods and materials, sub-assemblies held between manufacturing stages which have undergone some change but not completed; Maintenance/repair/operating (MRO) - necessary to keep machinery and processes productive; Finished goods completed products ready for sale or distribution; and Goods in transit $[17,5]$. Good inventory management assures continuous supply and minimizes inventory investment while achieving customer service objectives. The demand for inventory in an organization can take the form of either independent demand or dependent demand. Independent demand items are finished goods or other items sold to someone outside the company while dependent demand items are materials or component parts used in the production of another item (e.g., finished product).

\section{Inventory Costs}

Inventory represents an investment by an organization and the cost are categorized thus: costs of holding stock, costs of obtaining stock, and stock out costs while the cost of maintaining inventory is included in the final price paid by the consumer [15]. Costs of holding inventory refer to money incurred to keep and maintain stock of goods in storage. These costs are also known as carrying costs and includes the opportunity cost of reduced responsiveness to customers' changing requirements, slowed introduction of improved items, and the inventory's value and direct expenses, since that money could be used for other purposes. Some of the identified costs are interest on capital invested in the stock, storage charges such as rent, lighting, heating, refrigeration etc, stores staffing, equipment maintenance and running costs, handling costs, audit, stocktaking or perpetual inventory costs, Insurance and security, Deterioration and security, Pilferage, damages etc. Costs of obtaining inventory are sometimes known as ordering costs, include the following: the clerical and administrative costs associated with the purchasing, accounting and goods received departments; transport costs; and where goods are manufactured internally, the set up and tooling costs associated with each production run. Stocks out costs are costs associated with running out of stock. The avoidance of these costs is the basic reason why stocks are held in the first instance. These costs include lost contribution through the lost sale caused by the stock out; loss of future sales because customers go elsewhere; loss of customer goodwill; cost of production stoppages caused by stock outs of W. I. P. or raw materials; labour frustration of stoppages; extra costs associate with urgent replenishment purchases; back order handling, and lost sales.

Inventory Control Systems

Inventory systems evolved by organizations are based on factors such as type of customer demand, time horizon, replenishment lead time, constraints and relevant costs. The overall goal of inventory is to have what is needed, and to minimize the number of times one is out of stock. Accurate records are a critical ingredient in production and inventory systems as it allows organization to focus on what is needed, enhances precise decisions about ordering, scheduling, and shipping. Incoming and outgoing record keeping must thus be accurate and stockrooms made secure. Inaccurate inventory records on can cause lost sales, disrupted operations, poor customer service, lower productivity, planning errors and expediting [14]. There are two broad types of inventory control systems namely; the Reorder Level and the Periodic Review Systems.

Reorder level system is also known as two-bin system whereby stock is segregated into two bins at predetermined re-order level set for each item. Stock is initially drawn from the first bin and a replenishment order issued when it becomes empty. When the stock level falls to the reorder level, a replenishment order is issued. The replenishment order quantity is the Economic Order Quantity (EOQ). Most 
organization operating the reorder level system maintains stock records with calculated re order levels which triggers off the required replenishment order. It is responsive to fluctuations in demand through automatic generation of a replenishment order at the appropriate time by comparison of stock level against reorder level and appropriate for widely differing types of inventory within the same firm.

Periodic review systems is called the constant cycle system where all stock items for all parts are reviewed periodically i.e. at fixed intervals so that there is more chance of obsolete items being eliminated and where necessary, a replenishment order is issued. The system can be compared with min-max system where orders are placed at specified fixed time interval for an order size to bring on-hand inventory up to the target inventory [14]. Economies in placing orders are however gained by spreading the purchasing office load more evenly, larger quantity discounts are obtained when a range of stock items is ordered at the same time from a supplier and because orders will always be in the same sequence, there may be production economies due to more efficient production planning being possible and lower set up cost. The quantity of the replenishment order is not a previously calculated EOQ, but is based upon the likely demand until the next review, the present stock level and the lead time while the replenishment order quantity variable quantities at fixed intervals as compared with the reorder level system where fixed quantities are ordered at variable intervals.

Review of Empirical Findings

Rajeev (2007) carried out an empirical evaluation of the machine tool on Small and Medium Enterprises (SMEs) in Bangalore. The study objective was to provide a guideline for enhancing investment management performance. Results from the study showed that inventory management has a decisive role in the enhancement of manufacturing industry's competitiveness. The study concluded that SMEs which are inventory management efficient are likely to perform better on the economic front and experience higher returns to scale. The study conducted by Adu-Bobi (2009) evaluated inventory management practices in Soap Manufacturing Firms in Ghana. A quantitative data collection was used to elicit information from staff members involved in inventory management operations. A purposive sampling approach was employed to identify ten employees directly involved in inventory management operations. The study revealed that the company operated a periodic review system as well as a just- in-time environment as regards inventory management practices. Adeyemi and Salami (2010) employed variance analysis, Economic Order Quantity (EOQ) Model and the Chi-square method in order to determine whether or not inventories in Nigeria Bottling Company, Ilorin Plant can be evaluated and understood using the various existing tools of optimization in inventory management. However, the study conducted by Kontuš (2014) provided evidence for a model equation that can be used by companies for calculating net savings from changes in inventory level as well as a new mathematical optimization model. Leung, Chen, Yadav and Gallien (2016) carried out a study on the Impact of Inventory
Management on Stock-Outs of Essential Drugs in SubSaharan Africa: Secondary Analysis of a Field Experiment in Zambia. The study employed Daily clinic storeroom stock levels of artemether-lumefantrine (AL) products covering 2009-2010 from 145 facilities which were used to determine historical stock-out levels and estimate demand patterns. Findings from the study showed that up to $30 \%$ of surveyed facilities stocked out of some AL product during the first quarter of 2010 despite ample inventory being simultaneously available at the national warehouse. Also, simulation experiments closely reproduced these results and linked them to the use of average past monthly issues and failure to capture lead-time variability in current inventory control policies. Shen, Deng, Lao and Wu (2017) identified key factors that influence inventory management practices, investigate efficient and effective inventory management approaches, and examine the impact of supplier cooperation on supply chain improvement which can be applied to similar problems encountered in actual manufacturing firms. The study found out that efficient and effective inventory management practices can provide practical guidance for foreign manufacturers in China. Sohail and Sheakh (2018) found a significant relationship between return on asset (ROA) and inventory days conducted from the study of inventory management system of Small Scale manufacturing Industry. Findings from the studies carried out by Kumar and Manohar (2011); Egberi and Egberi (2011); Imeokparia (2013), and Atnafu and Balda (2018) revealed that inventory management has significant relationship with performance. In furtherance to the above, this study shall extend the analysis carried by previous studies to examine Inventory Management as an impetus for increased Profitability in Manufacturing Firms.

\section{Methodology}

The methodology employed in this study is a simple statistical technique to generate empirical evidences. Secondary data spanning for a period of 10 years from 2002 to 2011; were sourced from annual reports and accounts of International Breweries Plc. This period was chosen because it covers the company's transformation, reorganization and restructuring which had impacted on its productivity and profitability. Data collated are presented in tables, graphs and charts for quick analysis and presentation of variables used. Variables used in the study are measured by Gross Profit (GRP) and five (5) elements of Inventories namely Raw materials, Work -in - $\quad$ Progress, Maintenance/repairs/operating, Finished Goods and Goodsin-transit spotlighted from the 10 years financial statements of the company. Simple linear regression model was formulated to empirically investigate the implication of the three components of inventory on profitability of International Breweries Plc. The model is specified functionally as:

$$
\text { Gross Profit }=\mathrm{f}(\text { Inv })
$$




$$
\mathrm{GRP}=\beta_{0}+\beta_{1} \operatorname{Inv}+\varepsilon
$$

Where; $\beta_{0}, \beta_{1}=$ represents the intercept, GRP = represents Gross Profit, Inv = Summation of all inventory of the company, $\varepsilon=$ represents every other variable not captured in the study.

\section{Data Analysis, Presentation and Discussion of Findings}

Growth trend in Gross profit and Inventory

From the chart below, gross profit showed a relatively steady growth from 2001 to 2005 but declined marginally in 2006 resulting in a gross loss. It again began to improve consistently from 2007, the trend which was sustained though-out the years considered in the study. Inventory is expected to have a direct impact on gross profit indicating that gross profit should normally move in the direction of inventory. The chart thus showed upward movement in inventory which could be contrasted with the gross profit but the movement peaked in 2010 and declined in 2011. However, gross profit did not respond to the decline of inventory as it would normally be expected.

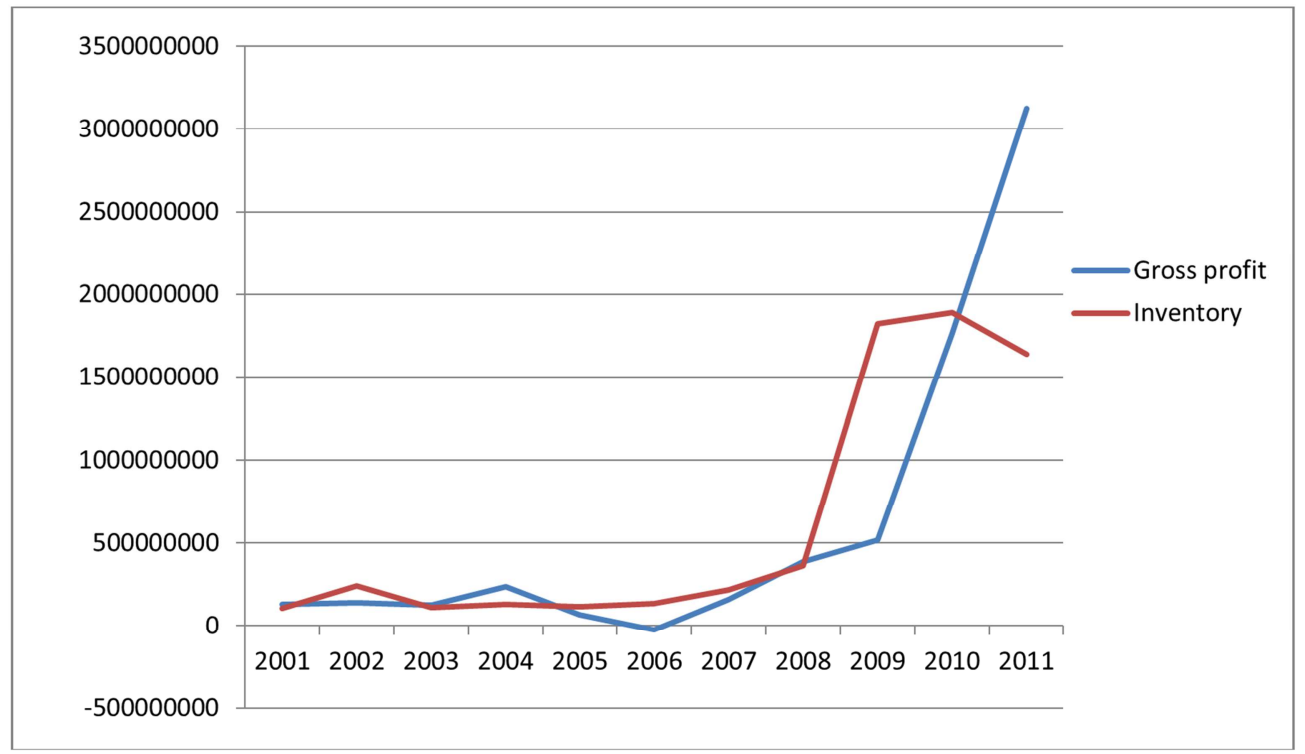

Figure 1. Growth trend in Gross profit and Inventory.

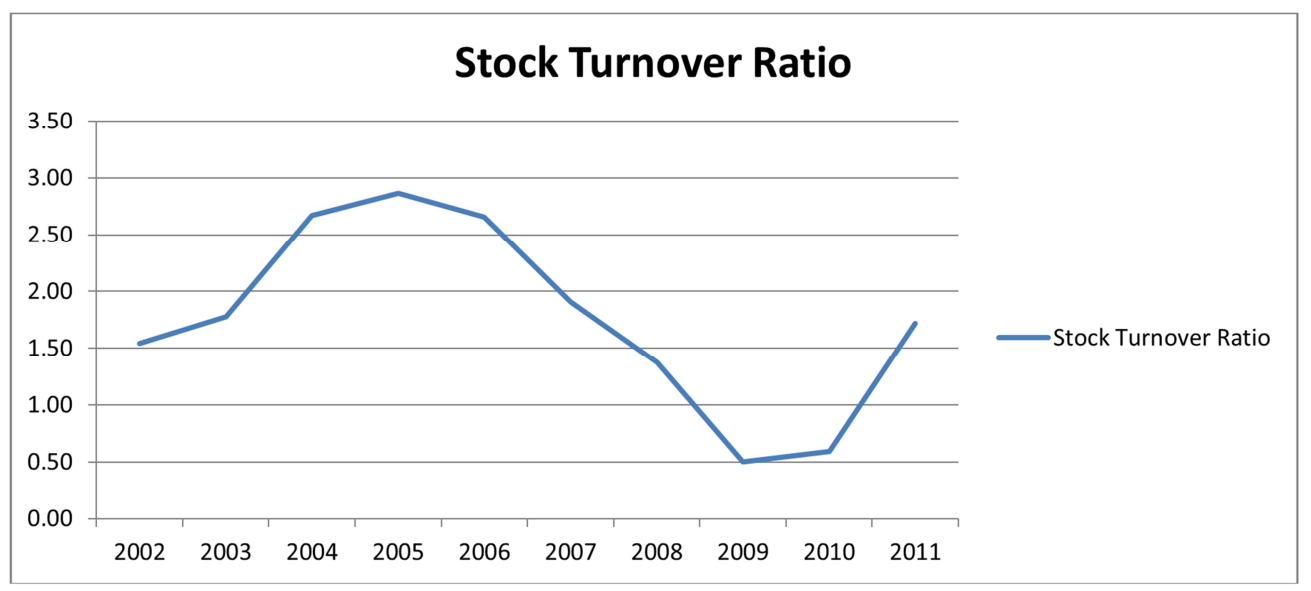

Figure 2. Stock turnover ratio.

\section{Stock Turnover Ratio}

Stock turnover ratio (STR) captures the relationship between cost of sales incurred in generating total revenue and the inventory utilized for production and distribution. The STR is expected to indicate the number of times that the inventory is turned over to achieve the sales reported in each reporting period. The STR of the company does not show a consistent pattern. In 2002 and 2003, the STR is between
1.54 and 1.78 but between 2004 and 2006, it oscillated between 2.66 and 2.86 while in 2007, 2008, 2009, 2010 and 2011 , it showed $1.91,1.38,0.50,0.59$ and 1.72 respectively. This implies that the inventory of the company was put to the most efficient use in the period it reported the lowest turnover ratio which was year 2009 as the inventory of the company was turned over more quickly to achieve the sales reported in that period. The period with higher turnover ratio 
are indicative of inability of the company to effectively and efficiently utilize its inventory faster in achieving the sales for those periods. This could however be caused by factors such as low customer demand, high volume of slow moving items, obsolete materials etc.

Table 1. Pearson Correlation Coefficient.

\begin{tabular}{llll}
\hline & & Gross Profit & Inventory \\
\hline \multirow{2}{*}{ Pearson Correlation } & Gross Profit & 1.000 & .853 \\
& Inventory & .853 & 1.000 \\
Sig. (1-tailed) & Gross Profit & .001 & .001 \\
\hline
\end{tabular}

Source: Author's computation, 2019.

Table 2. Regression analysis

\begin{tabular}{llllll}
\hline $\mathbf{R}$ & $\mathbf{R}^{\mathbf{2}}$ & Adjusted $\mathbf{R}^{\mathbf{2}}$ & $\mathbf{F}$ & Sig. & Durbin-Watson \\
\hline .853 & .727 & .693 & 21.348 & .002 & 1.836 \\
\hline
\end{tabular}

a Predictors: (Constant), Inventory, Dependent Variable: Gross Profit.

\section{Correlations analysis}

Correlation analysis explained the degree of relationship that exists between the variables employed in the study. The result exhibited positive and strong relationship between Inventory (INV) and Gross Profits (GRP) showing that upward movement in the explanatory variable will result in increased level of performance recorded by International Breweries Plc by $85.3 \%$ at $5 \%$ level of significance.

Regression analysis

From the test carried out as summarized above, the result showed that $\mathrm{R}^{2}$ is $72.7 \%$ while the adjusted $\mathrm{R}^{2}$ is $69.3 \%$ indicating that change in the dependent variable is largely captured by the explanatory variable. The result of Durbin Watson however stood at 1.836 which is within the acceptable level. The simple regression based model therefore gives the description of the interdependence between the variables captured in the model as shown in the above results. Gross Profit (GRP) was used to measure the profitability of International Breweries Plc during the period under study, while Inventory (INV) combines all the five components of inventory - Raw materials, Work-inprogress, Maintenance/repairs/operating, Finished goods and Goods in transit spotlighted from the company's financial statements. INV was regressed on GRP to assess the direction and degree of relationship of the two variables and whether there exist any at all. The results from the simple regression analysis carried out showed positive relationship between the variables. $72.7 \%$ of the variables that drive GRP which is the regressand were caused by INV, the regressor while only $27.3 \%$ were caused by variables not captured in the study.

\section{Conclusion and Recommendations}

From the result generated by the study, we can deduce that the efficient inventory management contribute significantly to profitability of manufacturing companies and by extension ensures reduction in ordering and carrying cost of inventory. This is in line with findings from other study which noted significant relationship between inventory management and performance, organizational growth and resources optimisation of manufacturing companies (Adeyemi \& Salami, 2010; Adu-Bobi, 2009; Atnafu and Balda (2018); Egberi \& Egberi 2011; Imeokparia, 2013; Kumar \& Manohar 2011; Rajeev, 2008). The study thus recommends that manufacturing companies should focus on improving on their inventory management system as it is capable of enhancing the survival, growth and stability of the companies. However, from the analysis carried out, a more efficient approach in utilizing inventory items should be adopted by management of International Breweries Plc to improve on its stock turnover ratio. Properly implemented Inventory Management System are significant in monitoring, tracking and recording receipts and issuance of inventory due to the direct effect it produce on company's profitability and growth. Consequent to our findings in this study, we posit that Inventory drives the profitability of a company.

\section{Appendix}

Table 3. Trend Analysis of Gross profit, Inventory, Cost of Sales and Stock Turnover.

\begin{tabular}{llllll}
\hline \multirow{2}{*}{ Years } & Gross Profit & \multicolumn{3}{c}{ Inventory } & Cost of Sales \\
\cline { 2 - 6 } & GRP & Log (GRP) & INV & Log (INV) & COS \\
\hline 2001 & $131,111,546$ & 8.12 & $107,614,196$ & 8.03 & $268,073,386$ \\
2002 & $141,579,012$ & 8.15 & $239,964,362$ & 8.38 & $312,153,022$ \\
2003 & $127,597,224$ & 8.11 & $110,615,348$ & 8.04 & $324,404,439$ \\
2004 & $237,032,704$ & 8.37 & $132,251,467$ & 8.12 & $357,671,323$ \\
2005 & $67,635,586$ & 7.83 & $117,682,124$ & 8.07 & $333,763,849$ \\
2006 & $-22,753,363$ & 7.36 & $133,578,581$ & 8.13 & $335,801,284$ \\
2007 & $161,656,662$ & 8.21 & $218,547,047$ & 8.34 & 2.67 \\
\hline
\end{tabular}




\begin{tabular}{llllll}
\hline \multirow{2}{*}{ Years } & Gross Profit & \multicolumn{3}{c}{ Inventory } & Cost of Sales \\
\cline { 2 - 6 } & GRP & Log (GRP) & INV & Log (INV) & COS \\
\hline 2008 & $386,477,580$ & 8.59 & $362,349,983$ & 8.56 & $545,443,464$ \\
2009 & $517,175,761$ & 8.71 & $1,821,402,897$ & 9.26 & $1,099,327,602$ \\
2010 & $1,764,575,072$ & 9.25 & $1,888,591,864$ & 9.28 & $3,030,370,638$ \\
2011 & $3,123,162,000$ & 9.49 & $1,636,460,000$ & 9.21 & 0.50 \\
\hline
\end{tabular}

Source: Annual reports and accounts of International Breweries Plc.

\section{References}

[1] Adeyemi, S. L., \& Salami A. O. (2010). Inventory Management: A Tool of Optimizing Resources in a Manufacturing Industry, A Case Study of Coca-Cola Bottling Company, Ilorin Plant. Journal of Social Sciences 23 (2), Pg 135-142.

[2] Adu-Bobi, K. A (2009). An Evaluation of Inventory Management Practices in Soap Manufacturing Firms in Ghana: the Case of Appiah - Menka Complex Ltd, Kumasi, Institutional Repository for Kwame Nkurumah University of Science and Technology (KNUST), Retrieved from http:/hdl.handle.net/123456789/913.

[3] Atnafu, D., \& Balda, A. (2018). The impact of inventory management practice on firms' competitiveness and organizational performance: Empirical evidence from micro and small enterprises in Ethiopia. Cogent Business \& Management, 5 (1), 1503219.

[4] Egberi, K. A \&Egberi, E. O. (2011). Inventory Control and Management as Effective and Efficient Tools in Achieving Organisational growth in Nigeria: A Case study of Eternit Limited, Sapele, Delta State.

[5] Heyl, J. (2011). Inventory Management, Operation Management Strategy Decisions. Pearson Education Inc., publishing as Prentice Hall.

[6] Imeokparia, L. (2013). Inventory Management System and Performance of Food and Beverages Companies in Nigeria. IOSR Journal of Mathematics (IOSR-JM) Volume 6, Issue 1, $P P$ 24-30. Retrieved from http://www.iosrjournals.org/iosr$\mathrm{jm} /$ papers/Vol6-issue1.

[7] Kumar, N. \& Manohar, V. (2011). An evaluation of the size in the management of inventory in Tamilnadu cement industry. Foundation for Organisational Research \& Education. Retrieved

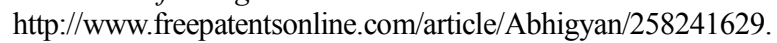

[8] Kotler, P. (2002). Marketing Management, 2nd Edition, the Millennium Edition, New Delhi: Prentice Hill of India.

[9] Kontuš, E. (2014). Management of inventory in a company. Ekonomski vjesnik: Review of Contemporary Entrepreneurship, Business, and Economic Issues, 27 (2), 245-256.

[10] Leung, N. H. Z., Chen, A., Yadav, P., \& Gallien, J. (2016). The impact of inventory management on stock-outs of essential drugs in Sub-Saharan Africa: secondary analysis of a field experiment in Zambia. PloS one, 11 (5), e0156026.

[11] Lucey, T. (2003), Costing, 5th Edition. London: AshfrodColour Press.

[12] Morris, C. (1995). Quantitative Approach in Business Studies: London: Pitman Publisher.

[13] Rajeev, N. (2008). Do inventory management practices affect economic performance? An empirical evaluation of the machine tool SMEs in Bangalore.International Journal of Management Science and Engineering Management, Vol. 3 No 4, pp. 312-320.

[14] Reid, D. \& Sanders, N. R. (2010), Operations Management, 4th Edition, Wiley.

[15] Rosenblatt, B. S. (1977). Modern Business - A Systems Approach. $2^{\text {nd }}$ Edition, Boston: Houghton Mifflin Co.

[16] Shen, H., Deng, Q., Lao, R., \& Wu, S. (2016). A case study of inventory management in a manufacturing company in China. Nang Yan Business Journal, 5 (1), 20-40.

[17] Stevenson, W. J. (2007). Inventory management, the McGrawHill Companies, Inc.

[18] Sohail, N \& Sheikh T. H. (2018). A Study of Inventory Management System Case Study. Journal of Dynamical and Control Systems, 10 (10), 1176-1190. 